\title{
Homenaje al Dr. Richard V. Lee (1937-2013)
}

'Editor, Revista Médica de Chile.

\author{
HUMBERTO REYES B. ${ }^{1}$
}

\section{A tribute to Richard V. Lee, M.D.}

Richard V. Lee, MD, MACP, FRGS, Professor of Medicine and Pediatrics and Obstetrics, Adjunct Professor of Anthropology and Social and Preventive Medicine. Director, Division of Maternal $\nleftarrow$ Adolescent Medicine, and Director, Division of Geographic Medicine, Department of Medicine, State University of New York at Buffalo, USA, passed away on May 7, 2013. His academic degrees and university positions are a vivid testimony of his wide professional interests and capabilities. As a humanist and ecologist, he became involved in a broad range of medical and research activities in the Brazilian Amazon, the Chilean Southern Andes, the African deserts and highlands, India, the Himalayas, and China. His extensive bibliography on ecology, the health status of geographically isolated populations and the role of physicians on cultural and macro environmental factors, has been summarized in his posthumous book "Out of Bounds. Medicine and The Hundred Acre Wood", recently published by the Royal Society of Medicine, London. The Sociedad Médica de Santiago-Chilean Society of Internal Medicine and its journal Revista Médica de Chile are indebted to his enthusiastic contributions and advice.

(Rev Med Chile 2013; 141: 1350-1352)

Key words: Ecology; Delivery of health care; History of Medicine; Humanities.

E 1 Dr. Richard V Lee ("Dick Lee") nació en Islip, Estado de Nueva York, EE. UU. de NA. $y$ fue nieto de inmigrantes chinos arribados a California con el apellido "Li", que americanizaron a "Lee". Tal como su padre, cursó estudios en Yale College, graduándose en 1960 como BS en Zoología. Estudió medicina en Yale University School of Medicine, recibiendo el título de médico en 1964. Continuó con una residencia en Medicina Interna, en la misma universidad (1964-1966). Comisionado por el United States Public Health Service, se desempeñó como médico general en la reserva indígena de Fort Peck, en Montana (19661969). Regresó a la Universidad de Yale para recibir entrenamiento en infectología, inmunología y reumatología (1970-1972), incorporándose como docente clínico de medicina general, ambulatoria y de emergencias (1972-1976).

En 1976 se trasladó a la Facultad de Medicina de la State University of New York at Buffalo, donde se desempeñó como Profesor de Medicina, de

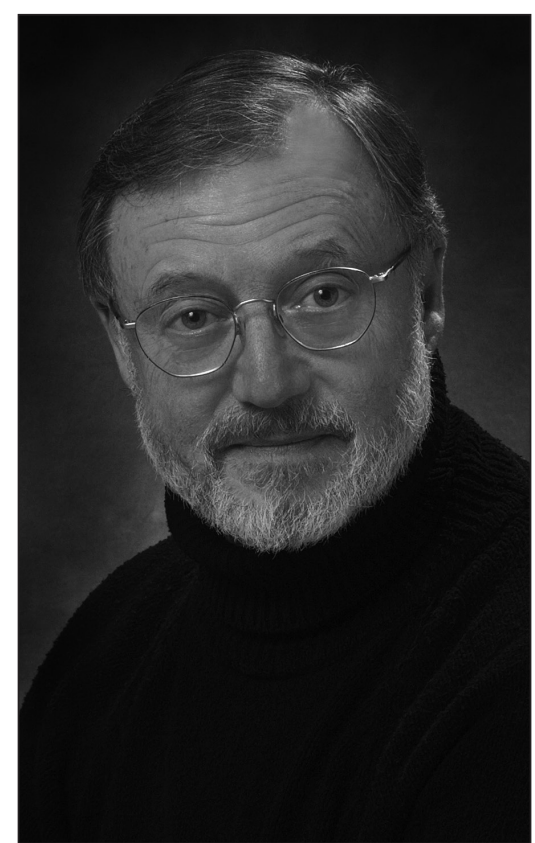


Pediatría y de Obstetricia, Profesor Adjunto de Antropología y de Medicina Preventiva y Social. Fue Director de la División de Medicina Materna y de Adolescentes, y Director de la División de Medicina Geográfica, en el Departamento de Medicina de esa universidad. Obtuvo los grados académicos de Master del American College of Physicians y de Fellow de la Royal Geographical Society. Fue uno de los miembros fundadores de la International Society of Obstetric Medicine. Estos multifacéticos títulos académicos se originaron por su variadísima actividad en ámbitos geográficos muy distantes a su lugar de residencia, a lo cual contribuyó su rol como director médico en una empresa privada ("Ecology and Environment, Inc.") que ofrece servicios de consultoría en medicina ambiental, en cualquier localidad del planeta que los requiera.

En la década de 1970 integró equipos que atendieron grupos aborígenes en la zona amazónica de Brasil y visitó comunidades indígenas en la cordillera andina de la Araucanía, en Chile.

En la década de 1980 colaboró con la Escuela de Medicina de Georgetown University organizando trabajos de terreno de estudiantes de medicina y docentes, en campos de refugiados de Laos, Cambodia y Vietnam. En 1982 inauguró un programa médico de la State University of New York at Buffalo para investigar la situación de salud y dar atención médica a habitantes del Valle de Warwan, en Cachemira, a grupos nómades en la frontera norte de Kenya, y a habitantes de varias aldeas de Zanskar, en Ladakh, vecino a Tibet.

El notable interés profesional y académico que tuvo Dick por los condicionantes ambientales y culturales de la salud en poblaciones aisladas y remotas, se ha reflejado en numerosas publicaciones en revistas médicas generales, de epidemiología y salud pública, de infectología, y en libros sobre estas materias. Esas publicaciones culminaron con un libro póstumo, de su sola autoría, cuya edición dirigió hasta el momento de su inesperado fallecimiento, el 7 de mayo de 2013. La Royal Society of Medicine, en Londres, imprimió esta obra, titulada "Out of Bounds. Medicine and The Hundred Acre Wood", que recopila la extraordinaria experiencia vivida por Dick y su pensamiento frente a nuestra profesión, su estado actual y las perspectivas de la educación y la asistencia médicas.

Dick Lee y Susan Bradley contrajeron matrimonio en 1960. Susan lo acompañó en muchos de sus emprendimientos en tierras lejanas. Establecieron su residencia en una granja "Many Barn Farm" en las afueras de Buffalo (Orchard Park), donde cultivaban frutas y hortalizas que, en los inviernos, compartían con zorros y otras especies silvestres que se atrevían a visitarlos por senderos despejados en la nieve. Tuvieron dos hijos -Mathew y Benjamin- y dos nietas: Aurora y Lillian.

Dick y Susan visitaron Chile en varias oportunidades, conociendo hasta los lagos y montañas de Última Esperanza. En uno de sus viajes, Dick manifestó al ingeniero Ricardo Katz (hijo) su interés por conocer el extraño fenómeno de la colestasis gravídica en Chile. Ricardo lo guió para contactarme y paulatinamente se generó una amistad personal y familiar con Dick. En 1999, Dick fue invitado a integrar el Comité Asesor Internacional de la Revista Médica de Chile, convirtiéndose en un consejero y colaborador incansable, aportando manuscritos propios, de notable interés (ver listado, abajo). En el año 2012, la Comisión Científica del XXXI World Congress of Internal Medicine, organizado por la Sociedad Médica de Santiago - Chilean Society of Internal Medicine, lo invitó a dar tres conferencias, entre ellas la de clausura del Congreso. El 16 de noviembre de 2012 repitió su conferencia "Solidarity in Medicine: The Role of Medical Students and Young Physicians" para estudiantes de medicina, docentes y autoridades de la Universidad Andrés Bello, siendo invitados después -Dick y Susan- a conocer la estación de biología marina de esta universidad en la caleta de Quintay. Esa fue su despedida de nuestro país.

El inquieto corazón de Dick se detuvo, definitivamente, una tarde en que desbrozaba su granja. Su universidad le rindió un homenaje póstumo el 24 de junio de 2013: "Celebrating the Life and Legacy of Richard V. Lee", con una ceremonia que reunió al mundo académico, sus familiares y amigos. La Revista Médica de Chile y la Sociedad Médica de Santiago expresan en este obituario su agradecimiento a un amigo excepcional. 
Publicaciones del Dr. Richard V. Lee en la Revista Médica de Chile

1. Lee, Richard V. Nausea and vomiting of pregnancy: An evolutionary hypothesis. Rev Med Chile, May 2002, vol.130, no.5, p. 580584.

2. Lee, Richard V. and De Swiet, Michael. Obstetric Medicine: Interdisciplinary care for pregnancy and for women wishing to conceive. Rev Med Chile, Jan 2006, vol.134, no.1, p. 109-114.

3. Lee, Richard V. Medical journals: Old, not senescent. A tribute to Revista Médica de Chile on its $135^{\text {th }}$ Anniversary. Rev Med Chile, July 2007, vol.135, no.7, p. 823-828.
4. Lee, Richard V.A letter from the United States: The romance of medicine -voyages and heroes. Rev Med Chile, Mar 2009, vol.137, no.3, p. 438443.

5. Lee, Richard V. A letter from the United States: The fox in our backyard - Science, Serendipity and Surprise. Rev Med Chile, Nov 2009, vol.137, no.11, p. 1502-1507.

6. Lee, Richard V. Darwin's Earthquake. Rev Med Chile, July 2010, vol.138, no.7, p. 897-901.

7. Lee, Richard V. The broken branch: Darwin's evolutionary tree and the progress of Medicine, the evolution of specialism and generalism. Rev Med Chile, Feb 2013, vol.141, no.2, p. 220-226. 